\title{
Comportamento de Cultivares de Milho no Consórcio com Brachiaria brizantha NA PRESENÇA E AUSÊNCIA DE FORAMSUlfuRON + IODOSULFURON-METHYL PARA O MANEJO DA FORRAGEIRA ${ }^{1}$
}

\author{
Behavior of Corn Cultivars Intercropped with Brachiaria brizantha in the Presence and \\ Absence of Sprayed Foramsulfuron + Iodosulfuron-Methyl
}

\author{
FREITAS, F.C.L. ${ }^{2}$, SANTOS, M.V. ${ }^{3}$, MACHADO, A.F. L. ${ }^{4}$, FERREIRA, L.R. ${ }^{5}$, FREITAS, M.A.M. ${ }^{6}$ e \\ SILVA, M.G.O. ${ }^{7}$
}

\begin{abstract}
RESUMO - O objetivo deste trabalho foi avaliar o comportamento de cultivares de milho no cultivo consorciado com Brachiaria brizantha cv. MG5 Vitória e o efeito da aplicação de subdose da mistura dos herbicidas foramsulfuron + iodosulfuron-methyl no manejo de B. brizantha, numa área sem interferência de plantas daninhas, em sistema de plantio direto. Cinco cultivares de milho foram avaliados: um híbrido simples (AGN 30A00), um híbrido simples modificado (30K75), dois híbridos duplos (RG2A e AGN 25A23) e uma variedade (UFV M100), conduzidos em dois sistemas de manejo de B. brizantha: com e sem aplicação de $30 \mathrm{~g} \mathrm{ha}^{-1}$ da mistura comercial de foramsulfuron + iodosulfuron-methyl $\left(300+20 \mathrm{~g} \mathrm{~kg}^{-1}\right)$. $\mathrm{O}$ delineamento experimental foi de blocos ao acaso, em parcelas subdivididas, com quatro repetições, sendo os cultivares de milho colocados nas parcelas principais e os sistemas de manejo de $B$. brizantha nas subparcelas. A aplicação do herbicida foi realizada aos 30 dias após a emergência do milho (DAE). Aos 30, 60, 90 e 120 DAE foram efetuadas avaliações da massa seca da parte aérea de $B$. brizantha. Para cultura do milho, na ocasião da colheita, que ocorreu aos 120 DAE, avaliaram-se a altura de plantas, o estande final e o rendimento de grãos. Verificaram-se maiores valores do rendimento de grãos de milho para os cultivares 30K75, AGN 30A00 e RG2A. Os híbridos simples (AGN 30A00) e simples modificado (30K75) foram mais competitivos com a forrageira, reduzindo o acúmulo de massa seca, em relação aos híbridos duplos e à variedade. A aplicação do foramsulfuron + iodosulfuron-methyl reduziu a taxa de crescimento de $B$. brizantha, sem, no entanto, afetar o rendimento de grãos de milho. Com isso, fica demonstrado que a forrageira não influenciou o rendimento da cultura, com o consórcio implantado em semeadura simultânea.
\end{abstract}

Palavras-chave: integração lavoura-pecuária, renovação de pastagem, manejo cultural, competição.

ABSTRACT - This work aimed to evaluate the performance of the corn cultivars intercropped with Brachiaria brizantha $c v$. MG5 Vitoria and the effect of applying a mixture of the herbicides foramsulfuron + iodosulfuron-methyl on B. brizantha management, in an area with no weed interference, under no-tillage system. Five corn cultivars were evaluated: a simple hybrid (AGN 30AOO), a simple modified hybrid (3OK75), two double hybrids (RG2A and AGN 25A23) and a variety (UFV M1OO), in two B. brizantha management systems: with and without application of foramsulfuron + iodosulfuron-methyl $(9.0+0.6 \mathrm{~g} \mathrm{ha-1})$, arranged in a randomized block design, in a split plot, with four replications. The corn cultivars and the $\boldsymbol{B}$. brizantha management systems were placed in the plot and split plot, respectively. Herbicide application was accomplished 30 days after corn emergence (DAE). At 30, 60, 90 and 120 DAE, B. brizantha was evaluated based on dry mass. During harvest time, plant height, final stand and productivity were evaluated. Higher

1 Recebido para publicação em 24.5.2007 e na forma revisada em 27.2.2008.

2 Professor Adjunto do Dep. de Ciências Vegetais da UFERSA, <fclaudiof@yahoo.com.br>; ${ }^{3}$ Doutoranda em Zootecnia-UFV; ${ }^{4}$ Doutorando em Fitotecnia-UFV; ${ }^{5}$ Professor Associado do Dep. de Fitotecnia da UFV; ${ }^{6}$ Estudante de graduação do curso de Agronomia-UFV; ${ }^{7}$ Estudante de graduação do curso de Agronomia-UFERSA. 
values of crop productivity in the corn cultivars 30K75, AGN 30AO0 and RG2A were verified. The simple hybrid and simple modified hybrid were more competitive in $\boldsymbol{B}$. brizantha, decreasing dry mass accumulation compared to the double hybrids and the variety. The application of foramsulfuron + iodosulfuron-methyl decreased $\boldsymbol{B}$. brizantha growth rate, with no influence on corn productivity. Overall, it was verified that the B. brizantha does not affect crop productivity when intercrop occurs simultaneously.

Keywords: crop-livestock integration, pasture renewal, cultural management, competition.

\section{INTRODUÇÃO}

O plantio de espécies forrageiras consorciadas com culturas anuais tem se mostrado uma técnica eficiente e economicamente viável como método de formação, recuperação e renovação de pastagens (Jakelaitis et al., 2004; Freitas et al., 2005a, b). O estabelecimento do consórcio pode acontecer através da semeadura simultânea da cultura anual e da forrageira, ou a partir da semeadura da cultura anual e da germinação natural da forrageira de sementes existentes no solo. Após a colheita da cultura anual, tem-se a pastagem formada e disponivel para utilização animal. Várias culturas anuais têm sido utilizadas para essa finalidade, com maior preferência para a cultura do milho destinado à produção de grãos ou silagem, devido à tradição de cultivo, ao grande número de cultivares comerciais adaptados às diferentes regiões ecológicas do Brasil, à excelente adaptação quando utilizado em consórcio e à facilidade de cultivo (Silva et al., 2004). A implantação dessa modalidade de consórcio pode ser feita de diversas formas. A semeadura simultânea com duas linhas da forrageira na entrelinha do milho tem apresentado melhores resultados em relação à cultura e à forrageira, tanto em consórcio com o milho destinado à produção de grãos (Jakelaitis et al., 2005) como para silagem (Freitas et al., $2005 a, b)$.

Diversos trabalhos têm sido realizados no sentido de estudar estratégias para o manejo do consórcio de milho destinado à produção de grãos ou silagem com gramineas forrageiras. Estudos de consórcios de Brachiaria sp. com milho para produção de grãos (Jakelaitis et al., 2004, 2005) ou silagem (Freitas et al., 2005b) em áreas com infestação de plantas daninhas gramineas demonstram a necessidade da aplicação de subdoses de herbicidas graminicidas, como o nicosulfuron ou foramsulfuron + iodosulfuron-methyl, no sentido de manejar as plantas daninhas e reduzir a taxa de crescimento da espécie forrageira.

O sistema de plantio direto pode reduzir significativamente a intensidade de infestação de plantas daninhas em áreas agrícolas, em razão do efeito físico da cobertura e da liberação de substâncias alelopáticas, que alteram as condições de germinação das sementes e a emergência das plântulas (Araújo \& Rodrigues, 2000; Jakelaitis et al., 2003; Trezzi $\&$ Vidal, 2004; Machado et al., 2005). Com isso, em áreas cultivadas no sistema de plantio direto com boa cobertura do solo e banco de sementes de plantas daninhas reduzido, como é o caso de algumas áreas anteriormente ocupadas por pastagens, é comum não ocorrer interferência de plantas daninhas, tornandose necessário conhecer melhor o comportamento das espécies consorciadas nessas condições para definir as estratégias de manejo a serem adotadas. Em consórcio de milho para silagem $\operatorname{com} B$. brizantha CV MG5, implantado em área sem infestação de plantas daninhas, no sistema de plantio direto, a aplicação de nicosulfuron reduziu a taxa de crescimento de $B$. brizantha, sem, no entanto, influenciar a produtividade de milho para silagem (Freitas et al., 2005a).

O milho é considerado um ótimo competidor com plantas de menor porte, como é o caso das braquiárias, devido, principalmente, à sua expressiva vantagem sobre a forrageira, evidenciada pela maior taxa de acúmulo de massa seca produzida nos estádios iniciais de desenvolvimento (Silva et al., 2004). Apresenta elevada capacidade de interceptação da radiação fotossinteticamente ativa ao longo de seu dossel, o que reduz a quantidade desse recurso para as outras espécies. Entretanto, essa 
interceptação varia conforme as características morfológicas do cultivar, como altura de planta e conformação das folhas, além da população utilizada.

Entre os cultivares de milho, os híbridos simples e simples modificados possuem menor variabilidade genética, formando populações uniformes e, normalmente, com porte mais baixo, em relação aos cultivares tecnicamente menos desenvolvidos, como os híbridos duplos, $\mathrm{e}$, principalmente, às variedades. Os híbridos simples possuem, também, arquitetura foliar moderna, com folhas eretas, permitindo trabalhar com estande mais elevado, que, somado ao maior potencial genético, possibilita obter maior rendimento de grãos (Sawazaki \& Paterniani, 2004). No entanto, esses cultivares são indicados apenas para condições de elevado nivel tecnológico, enquanto os cultivares mais rústicos são adequados para niveis tecnológicos mais baixos, com menor custo de produção.

Este trabalho foi proposto com o objetivo de avaliar o comportamento de cultivares de milho consorciados com $B$. brizantha, bem como o manejo desta planta no consórcio, numa área sem infestação de plantas daninhas, em sistema de plantio direto.

\section{MATERIAL E MÉTODOS}

O experimento foi conduzido no campus da Universidade Federal de Viçosa, em Viçosa-MG, em uma área com Argissolo Vermelho-Amare1o, declividade de 5 a 10\%, em sucessão à pastagem degradada de capim-gordura (Melinis minutiflora), com alta infestação de capim-sapé (Imperata brasiliensis) e com baixa expectativa de ocorrência de plantas daninhas, em função da boa cobertura do solo com palhada e da observação de áreas próximas com condições semelhantes, cultivadas em anos anteriores. A análise química do solo revelou $\mathrm{pH}$ em água de 5,4; CTC (T), Ca e Mg de 4,8; 3,96; 1,2; e $0,4 \mathbf{c m o l}_{\mathrm{c}} \mathrm{dm}^{-3}$, respectivamente; P e K de 2,3 e $33 \mathrm{mg} \mathrm{dm}^{-3}$, respectivamente; $2,87 \mathrm{dag} \mathrm{kg}^{-1}$ de matéria orgânica; e 12,7 de P-rem.

A área foi submetida à aplicação de 2,0 t ha ${ }^{-1}$ de calcário, com PRNT de $80 \%$, em superfície, e à dessecação com $1,8 \mathrm{~L} \mathrm{ha}^{-1}$ de glyphosate e $0,36 \mathrm{~L} \mathrm{ha}^{-1}$ de 2,4-D, no mês de maio de 2004. Na ocasião da dessecação, a área apresentava excelente cobertura do solo, que se manteve durante o período experimental.

Foram avaliados cinco cultivares de milho - um híbrido simples (AGN 30A00), um híbrido simples modificado (30K75), dois híbridos duplos (RG2A e AGN 25A23) e uma variedade (UFVM 100) - e dois sistemas de manejo de $B$. brizantha: com e sem aplicação de $30 \mathrm{~g} \mathrm{ha}^{-1}$ da mistura foramsulfuron + iodosulfuron-methyl $\left(300+20 \mathrm{~g} \mathrm{~kg}^{-1}\right)$. O delineamento experimental foi em blocos ao acaso, no esquema de parcelas subdivididas, com quatro repetições, sendo os cultivares de milho colocados nas parcelas principais e os sistemas de manejo de $B$. brizantha nas subparcelas, com quatro repetições. As unidades experimentais (subparcelas) foram constituídas de quatro fileiras de milho espaçadas de $1,0 \mathrm{~m}$, com $6,0 \mathrm{~m}$ de comprimento. Foram consideradas como área útil as duas fileiras centrais, desconsiderando-se $0,50 \mathrm{~m}$ das duas extremidades.

A semeadura do milho foi feita em 20 de outubro de 2004 , com oito sementes por metro de fileira. Aos dez dias após a emergência (DAE) foi realizado desbaste, deixando sete plantas por metro de fileira para os híbridos simples e simples modificados (AGN $30 A 00$ e 30K75) e cinco para os híbridos duplos (RG2A e AGN 25A23) e a variedade (UFVM 100). A adubação utilizada na semeadura foi de $500 \mathrm{~kg} \mathrm{ha}^{-1}$ da formulação 8-28-16 (N-P-K). A semeadura de $B$. brizantha $\mathrm{cv}$. MG5 Vitória foi realizada simultaneamente à do milho, com semeadora múltipla (Semeato SHM 11/13), em duas linhas espaçadas entre si de $0,5 \mathrm{~m}$, na entrelinha da cultura do milho, à profundidade de $2 \mathrm{~cm}$, usando $5 \mathrm{~kg} \mathrm{ha}^{-1}$ de sementes, com valor cultural de $76 \%$. A adubação de plantio foi feita apenas nas linhas do milho.

A adubação de cobertura do milho e de $B$. brizantha foi realizada aos 35 dias após emergência do milho (DAE), com aplicação de $90 \mathrm{~kg} \mathrm{ha}^{-1}$ de $\mathrm{N}$, na forma de uréia.

A aplicação do herbicida foi feita com pulverizador costal pressurizado com $\mathrm{CO}_{2}$, mantendo a pressão constante de $200 \mathrm{kPa}$, sendo a barra equipada com dois bicos TT 110.02, espaçados de $1,0 \mathrm{~m}$ e calibrados para aplicar o equivalente a $100 \mathrm{~L} \mathrm{ha}^{-1}$ de calda. A aplicação do herbicida foi efetuada aos $30 \mathrm{DAE}$, ocasião em que as plantas de $B$. brizantha apresentavam, em 
média, duas a três folhas. As condições climáticas no momento da aplicação eram de solo úmido, velocidade do vento inferior a $5 \mathrm{~km} \mathrm{~h}^{-1}$, temperatura do ar em torno de $25{ }^{\circ} \mathrm{C}$ e umidade relativa entre 80 e $85 \%$, não tendo ocorrido chuva no dia da aplicação.

Aos 30, 60, 90 e 120 DAE foram efetuadas avaliações da massa seca da parte aérea de $B$. brizantha, por meio de duas amostragens em $0,25 \mathrm{~m}^{2}$ por unidade experimental. Após a colheita, as plantas foram levadas para secagem em estufa com circulação forçada de ar, à temperatura de $60-70{ }^{\circ} \mathrm{C}$, até peso constante. Na cultura milho, por ocasião da colheita, aos 120 DAE, na área útil das subparcelas foram realizadas avaliações de: altura de plantas, obtida a partir da medição entre a distância do solo e a extremidade basal do limbo da última folha, por meio de amostragem aleatória de dez plantas; número de plantas, para obtenção do estande final; e rendimento de grãos, estimado a partir da massa de grãos, com umidade corrigida para $15 \%$.

Os dados obtidos foram submetidos à análise de variância para verificação dos efeitos dos fatores cultivares de milho e sistemas de manejo de $B$. brizantha e da interação entre estes. As médias foram comparadas pelo teste $\mathrm{F}$, para os sistemas de manejo de $B$. brizantha, e pelo teste de Duncan, para os cultivares de milho, a $5 \%$ de probabilidade.

\section{RESULTADOS E DISCUSSÃO}

Os fatores cultivares de milho e manejo de $B$. brizantha comportaram-se de modo independente em todas as características avaliadas, uma vez que não foi detectada interação significativa entre eles. Com isso, os resultados de cada fator serão discutidos separadamente.

A aplicação da subdose da mistura dos herbicidas foramsulfuron + iodosulfuron-methyl reduziu a taxa de crescimento de $B$. brizantha, com queda expressiva no acúmulo de massa seca, observada a partir dos $60 \mathrm{DAE}$, até a colheita do milho, que ocorreu aos $120 \mathrm{DAE}$ (Tabela 1). No entanto, a altura e a população de plantas e a produção de milho não foram influenciadas pela aplicação do herbicida (Tabela 2). Constatou-se que $B$. brizantha não afetou a cultura do milho, pois seu crescimento inicial foi mais lento em relação à cultura principal. Segundo Ramos \& Pitelli (1994), o período crítico de prevenção à interferência, ou seja, período no qual a convivência de plantas daninhas afeta a produtividade da cultura, para o milho é de 16 a 42 dias após a emergência. Nessa fase, as plantas de $B$. brizantha apresentavam taxa de crescimento muito baixa, representada pelo reduzido acúmulo de massa seca (Tabelas 1 e 3). Entretanto, o milho, por volta dos 40 dias após emergência, já promovia o fechamento do dossel, intensificando a competição por luz e inibindo o crescimento da forrageira, que, por ser uma planta com mecanismo fotossintético tipo $\mathrm{C}_{4}$, demanda alta luminosidade para seu pleno desenvolvimento. Com isso, o milho demonstrou ser um competidor eficiente $\operatorname{com} B$. brizantha, por desenvolver-se rapidamente, restringindo a passagem da luz fotossinteticamente ativa.

Esses resultados corroboram os observados por Freitas et al. (2005a), que não verificaram efeito da aplicação de subdose do herbicida nicosulfuron para restringir a taxa de crescimento de $B$. brizantha, na produtividade de milho para silagem, em área sem interferência de plantas daninhas. Entretanto, em áreas com interferência de plantas daninhas gramíneas, destinadas à produção de milho para grão (Jakelaitis et al., 2004, 2005) e para silagem (Freitas et al., 2005b), foi observado que havia necessidade da aplicação de subdoses de herbicidas graminicidas para manejar as plantas daninhas e reduzir a taxa de crescimento da braquiária. Cobucci (2001) relatou que, em vários experimentos sobre o consórcio de $B$. brizantha com o milho, a presença da forrageira não afetou essa cultura; contudo, em outros, foi necessário o uso do herbicida nicosulfuron em subdoses para reduzir o crescimento da forrageira. Portanto, a necessidade da aplicação de herbicidas graminicidas no consórcio de milho com Brachiaria sp., possivelmente, está relacionada à redução da competição exercida pelas plantas daninhas e não pela espécie forrageira, em condições de semeadura simultânea.

Vale ressaltar que a aplicação do herbicida para reduzir a taxa de crescimento da forrageira, apesar de não afetar a produção do milho em áreas sem interferência de plantas daninhas 
Comportamento de cultivares de milho no consórcio com...

Tabela 1 - Produção de massa seca de B. brizantha em função do sistema de manejo com e sem herbicida aos 30, 60, 90 e 120 dias após emergência do milho (DAE). Viçosa-MG, 2005

\begin{tabular}{|c|c|c|c|c|}
\hline \multirow{2}{*}{$\begin{array}{c}\text { Manejo de } \\
\text { B. brizantha }\end{array}$} & \multicolumn{4}{|c|}{ Massa seca de B. brizantha $\left(\mathrm{kg} \mathrm{ha}^{-1}\right)$} \\
\cline { 2 - 5 } & $30 \mathrm{DAE}$ & $60 \mathrm{DAE}$ & $90 \mathrm{DAE}$ & $120 \mathrm{DAE}$ \\
\hline Com herbicida $^{1 /}$ & $46,64 \mathrm{a}^{\frac{2}{}}$ & $133,6 \mathrm{~b}$ & $640,44 \mathrm{~b}$ & $1.464,0 \mathrm{~b}$ \\
\hline Sem herbicida & $47,72 \mathrm{a}$ & $734,4 \mathrm{a}$ & $2.165,42 \mathrm{a}$ & $3.659,2 \mathrm{a}$ \\
\hline CV $(\%)$ & 17,9 & 27,3 & 30,3 & 19,3 \\
\hline
\end{tabular}

1/ O manejo de B. brizantha foi feito com ou sem a aplicação de $30 \mathrm{~g} \mathrm{ha}^{-1} \mathrm{da}$ mistura foramsulfuron + iodosulfuron-methyl $\left(300+20 \mathrm{~g}\right.$ kg $\left.{ }^{1}\right)$, aos 30 DAE.

2/ Nas colunas, médias seguidas pela mesma letra não diferem entre si pelo teste $\mathrm{F}$ a $5 \%$ de probabilidade.

Tabela 2 - Altura de plantas, população e rendimento de grãos de milho em função do sistema de manejo com e sem herbicida. Viçosa-MG, 2005

\begin{tabular}{|l|c|c|c|}
\hline $\begin{array}{c}\text { Manejo de } \\
\text { B. brizantha }\end{array}$ & $\begin{array}{c}\text { Altura de plantas de milho } \\
(\mathrm{cm})\end{array}$ & $\begin{array}{c}\text { População na ocasião da } \\
\left.\text { colheita (plantas ha }{ }^{-1}\right)\end{array}$ & $\begin{array}{c}\text { Rendimento de milho } \\
\left(\mathrm{kg} \mathrm{ha}^{-1}\right)\end{array}$ \\
\hline Com herbicida $^{\underline{1}}$ & $230,75 \mathrm{a}^{\underline{2} /}$ & $54.833,3 \mathrm{a}$ & $7.743,7 \mathrm{a}$ \\
\hline Sem herbicida & $230,20 \mathrm{a}$ & $56.250,0 \mathrm{a}$ & $8.004,6 \mathrm{a}$ \\
\hline CV $(\%)$ & 7,13 & 2,37 & 10,09 \\
\hline
\end{tabular}

1/ O manejo de $B$. brizantha foi feito com ou sem a aplicação de $30 \mathrm{~g} \mathrm{ha}^{-1} \mathrm{da}$ mistura foramsulfuron + iodosulfuron-methyl $\left(300+20 \mathrm{~g} \mathrm{~kg}{ }^{-1}\right)$, aos 30 dias após emergência do milho.

2/ Nas colunas, médias seguidas pela mesma letra não diferem entre si pelo teste F a 5\% de probabilidade.

Tabela 3 - Efeito de cultivares de milho sobre a produção de massa seca de B. brizantha aos 30, 60, 90 e 120 dias após emergência do milho (DAE). Viçosa, 2005

\begin{tabular}{|l|c|c|c|c|}
\hline \multirow{2}{*}{ Cultivares de milho } & \multicolumn{4}{|c|}{ Massa seca de B. brizantha $\left(\mathrm{kg} \mathrm{ha}^{-1}\right)$} \\
\cline { 2 - 5 } & $30 \mathrm{DAE}$ & $60 \mathrm{DAE}$ & $90 \mathrm{DAE}$ & $120 \mathrm{DAE}$ \\
\hline AGN 30A00 (HS) & $45,62 \mathrm{a}^{1 /}$ & $319,60 \mathrm{~b}$ & $1.211,90 \mathrm{bc}$ & $1.614,80 \mathrm{~b}$ \\
\hline 30K75 (HSm) & $37,45 \mathrm{a}$ & $343,60 \mathrm{~b}$ & $1.052,30 \mathrm{c}$ & $1.876,40 \mathrm{~b}$ \\
\hline 25A23 (HD) & $54,24 \mathrm{a}$ & $498,00 \mathrm{a}$ & $1.364,60 \mathrm{abc}$ & $3.051,20 \mathrm{a}$ \\
\hline RG 2A (HD) & $46,20 \mathrm{a}$ & $468,00 \mathrm{a}$ & $1.764,80 \mathrm{a}$ & $3.110,00 \mathrm{a}$ \\
\hline UFV M100 (VA) & $42,35 \mathrm{a}$ & $522,80 \mathrm{a}$ & $1.663,20 \mathrm{ab}$ & $3.150,80 \mathrm{a}$ \\
\hline
\end{tabular}

1/ Nas colunas, médias seguidas pela mesma letra não diferem entre si pelo teste de Duncan a 5\% de probabilidade, para os cultivares de milho.

$\mathrm{HS}=$ híbrido simples; $\mathrm{HSm}=$ híbrido simples modificado; $\mathrm{HD}=$ híbrido duplo; VA = variedade.

(Tabela 2), pode ser uma estratégia interessante no sentido de reduzir o acúmulo de massa por ocasião da colheita (Tabela 1), o que facilitaria o trabalho da colhedora.

De modo geral, a massa seca de $B$. brizantha foi influenciada pelos cultivares de milho, a partir dos $60 \mathrm{DAE}$, sendo mais afetada pelos híbridos simples (AGN 30A00) e simples modificado (30K75) (Tabela 3). Isso ocorreu, possivelmente, devido à maior competição interespecífica desses cultivares, como conseqüência do estande mais elevado, apesar do porte mais baixo (Tabela 4), proporcionando maior fechamento do dossel e, conseqüentemente, reduzindo a luminosidade fotossinteticamente ativa para $B$. brizantha. Borghi \& Crusciol (2007), avaliando espaçamentos de milho consorciado com B. brizantha, 
constataram que fileiras mais próximas resultaram em menor acúmulo de massa seca por parte da forrageira.

Com relação à cultura do milho, plantas de menor estatura foram observadas nos cultivares AGN $30 \mathrm{A00}$ e $30 \mathrm{~K} 75$, ao passo que maiores alturas foram observadas em RG2A e UFV M100 (Tabela 4). Esse fato já era esperado, pois, segundo Sawazaki \& Paterniani (2004), cultivares de milho híbrido simples e simples modificados, normalmente, possuem plantas mais baixas que os híbridos duplos e as variedades. A menor altura de plantas verificada nos híbridos simples, somada a outras características desses materiais, como a arquitetura foliar moderna, com folhas com angulação mais ereta, viabiliza o uso de populações mais elevadas (Argenta et al., 2001), conforme foi empregado neste trabalho. de grãos de milho decorrente do aumento da população de plantas verifica-se, principalmente, em híbridos de ciclo superprecoce e de baixa estatura. Apesar do rendimento de grãos inferior, os cultivares AGN 25A23 e UFV M100 apresentaram produção elevada, com valores superiores a $7 \mathrm{t} \mathrm{ha}^{-1}$.

A forrageira $B$. brizantha, cultivada nas entrelinhas do milho, não afetou o rendimento desta cultura, com o consórcio implantado em semeadura simultânea. A aplicação da mistura comercial de foramsulfuron + iodosulfuronmethyl reduziu o desenvolvimento de $B$. brizantha sem influenciar a produção do milho. Os cultivares de milho AGN $30 A 00$ e $30 \mathrm{~K} 75$ foram mais competitivos com a espécie forrageira em relação aos cultivares RG2A, AGN 25A23 e UFV M100, reduzindo o acúmulo de massa seca de $B$. brizantha.

Tabela 4 - Altura de plantas, população e rendimento de grãos de milho em função dos cultivares avaliados. Viçosa-MG, 2005

\begin{tabular}{|l|c|c|c|}
\hline \multicolumn{1}{|c|}{ Cultivares de milho } & $\begin{array}{c}\text { Altura de plantas de milho } \\
(\mathrm{cm})\end{array}$ & $\begin{array}{c}\text { População na ocasião da } \\
\left.\text { colheita (plantas ha }{ }^{-1}\right)\end{array}$ & $\begin{array}{c}\text { Rendimento de milho } \\
\left(\mathrm{kg} \mathrm{ha}^{-1}\right)\end{array}$ \\
\hline AGN 30A00 (HS) & $204,95 \mathrm{~d}_{-}^{1} /$ & $63.538 \mathrm{a}$ & $8.122,89 \mathrm{a}$ \\
\hline 30K75 (HSm) & $212,97 \mathrm{c}$ & $64.789 \mathrm{a}$ & $8.731,33 \mathrm{a}$ \\
\hline 25A23 (HD) & $226,00 \mathrm{~b}$ & $53.542 \mathrm{~b}$ & $7.022,30 \mathrm{~b}$ \\
\hline RG 2A (HD) & $252,91 \mathrm{a}$ & $47.708 \mathrm{c}$ & $8.265,25 \mathrm{a}$ \\
\hline UFV M100 (VA) & $255,62 \mathrm{a}$ & $48.119 \mathrm{c}$ & $7.198,97 \mathrm{~b}$ \\
\hline
\end{tabular}

1/ Nas colunas, médias seguidas pela mesma letra não diferem entre si pelo teste de Duncan a 5\% de probabilidade, para os cultivares de milho.

$\mathrm{HS}=$ híbrido simples; HSm= híbrido simples modificado; $\mathrm{HD}=$ híbrido duplo; VA = variedade.

O rendimento de grãos de milho variou em função dos cultivares estudados, com maiores valores verificados para os cultivares AGN 30A00, 30K75 e RG2A (Tabela 4). A maior produção observada para aqueles dois cultivares, os híbridos simples e simples modificados, também já era esperada, pois, segundo Sawazaki \& Paterniani (2004), esses materiais apresentam maior capacidade produtiva em condições de alto nível de insumos, como utilizado neste trabalho. Obviamente que essa maior capacidade produtiva pode ser conseqüência, também, da maior população de plantas utilizada para esses materiais. De acordo com Argenta et al. (2001), o aumento do rendimento

\section{LITERATURA CITADA}

ARAÚJO, A. G.; RODRIGUES, B. N. Manejo mecânico e químico da aveia preta e sua influência sobre a taxa de decomposição e o controle de plantas daninhas em semeadura direta de milho. Planta Daninha, v. 18, n. 1, p. $151-160,2000$

ARGENTA, G. et al. Resposta de híbridos simples de milho à redução no espaçamento entre linhas. Pesq. Agropec.

Bras., v. 36, n. 1, p. 71-78, 2001.

BORGHI, E.; CRUSCIOL, C. A. C. Produtividade de milho, espaçamento e modalidade de consorciação com Brachiaria brizantha em sistema plantio direto. Pesq. Agropec. Bras., v. 42 , n. 2 , p. $163-171,2007$. 
COBUCCI, T. Manejo integrado de plantas daninhas em sistema de plantio direto. In: ZAMBOLIM, L. Manejo integrado fitossanidade: cultivo protegido, pivô central e plantio direto. Viçosa, MG: Universidade Federal de Viçosa, 2001. p. 583-624.

FREITAS, F. C. L. et al. Formação de pastagem via consórcio de Brachiaria brizantha com o milho para silagem no sistema de plantio direto. Planta Daninha, v. 23, n. 1, p. $49-58,2005 \mathrm{a}$.

FREITAS, F. C. L. et al. Cultivo consorciado de milho para silagem com Brachiaria brizantha em sistema de plantio convencional. Planta Daninha, v. 23, n. 4, p. 635-644, $2005 b$.

JAKELAITIS, A. et al. Dinâmica populacional de plantas daninhas sob diferentes sistemas de manejo nas culturas de milho e feijão. Planta Daninha, v. 21, n. 1, p. 71-79, 2003.

JAKELAITIS, A. et al. Manejo de plantas daninhas no consórcio de milho com capim-braquiária (Brachiaria decumbens). Planta Daninha, v. 22, n. 3, p. 553-560, 2004

JAKELAITIS, A. et al. Influência de herbicidas e sistemas de semeadura de Brachiaria brizantha consorciada com milho. Planta Daninha, v. 23, n. 1, p. 59-67, 2005.
MACHADO, A. F. L. et al. Population dynamic of weeds in no-tillage and conventional crop systems. J. Environ. Sci. Health Part B - Pestic. Food Agric. Wastes, v. B40, p. $119-128,2005$

RAMOS, L. R. M.; PITELLI, R. A. Efeitos de diferentes períodos de controle da comunidade infestante sobre a produtividade da cultura do milho. Pesq. Agropec. Bras., v. 29, n. 10, p. 1523-1531, 1994.

SAWAZAKI, E.; PATERNIANI, M. E. A. Z. Evolução dos cultivares de milho no Brasil. In: GALVÃO, J. C. C.; MIRANDA, G. V. (Eds.). Tecnologias de produção do milho. Viçosa, MG: Universidade Federal de Viçosa, 2004. p. $55-84$.

SILVA, A. A.; JAKELAITIS. A.; FERREIRA, L. R. Manejo de plantas daninhas no sistema integrado agriculturapecuária. In: ZAMBOLIM, L.; FERREIRA, A. A.; AGNES, E. L. (Eds.). Manejo integrado: integração agriculturapecuária. Viçosa, MG: Universidade Federal de Viçosa, 2004 p. 117-169.

TREZZI, M. M.; VIDAL, R. A. Potencial de utilização de cobertura vegetal de sorgo e milheto na supressão de plantas daninhas em condições de campo: II - Efeitos da cobertura morta. Planta Daninha, v. 22, n. 1, p. 1-10, 2004. 